Dr Gary S. Robertshaw

is a marketing manager at Cox Insurance Holdings and $a$ fellow of the Institute of Direct Marketing.

Dr Norman E. Marr

is professor of marketing at the Huddersfield University Business School.
Keywords: consumer information, customer profiling, segmentation, targeting
Gary S. Robertshaw

15 Heron Close

Mountain, Queensbury, Bradford West Yorkshire BD13 1NR, UK Tel: +44 (0)1274 884387

E-mail:

g.robertshaw@btopenworld.com

\section{Are abstainers different from voluntary contributors of personal information? Implications for direct marketing practice}

\author{
Gary S. Robertshaw and Norman E. Marr \\ Received (in revised form): 25 May 2005
}

\begin{abstract}
The disclosure of detailed, non-transactional, individual-level consumer information for direct marketing purposes is essentially voluntary in nature. This raises the possibility that those consumers who elect to disclose such information may be atypical of the general population. Using 256 personal interviews and a case study this paper explores demographic and value-system differences between contributors of personal information and abstainers, and provides a phenomenological insight into the reasons underlying the differences.

The results of this study reveal that consumers who voluntarily contribute personal information are different to those who abstain, both qualitatively and with respect to values, prompting a reappraisal of current targeting and customer profiling methods.
\end{abstract}

\section{Background}

There is an increasing recognition within the literature of the failure of conventional, aggregated consumer classifications systems to segment and define the post-modern market adequately. ${ }^{1-9}$ In the post-modern era, attempting to match one umbrella positioning strategy to the needs of assumed amorphous consumer groups will inevitably be less successful than developing multiple personalised strategies. ${ }^{10,11}$ Essentially, the proliferation of splintering market subsegments demands a more precise mode of consumer classification.

In tandem, rapidly improving database technology has facilitated the faster storage, processing and modelling of vaster amounts of complex individual-level consumer information. ${ }^{12-19}$ Market fragmentation and increased consumer eclecticism, coupled with improvements in database technology, have now led to a growing number of companies abandoning mass-marketing techniques in favour of personalised marketing programmes that better meet the needs of the individual. ${ }^{20-22}$

Over the last decade the shift towards personalised forms of marketing has been accentuated by the advent of digital communication channels, including the internet, interactive television and mobile telephones, allowing the direct marketing industry increasingly to communicate and interact with individual consumers on a real-time basis. ${ }^{23,24}$ Aggregated 


\section{Increased requirement for individual-level consumer information}

systems of analysis, which previously involved a single decision to target one market segment, are now being superseded by millions of independent automated decisions to communicate with individual consumers at an appropriate time. Mass-marketing communications in single batches personalised to meet the specific requirements of the individual consumer are now both possible and profitable. ${ }^{25-28}$

The evolution of personalised marketing programmes is, however, dependent on the availability of up-to-date and detailed, individual-level consumer information. While individual-level transactional data can be obtained from customer records, the acquisition of detailed nontransactional information relating to interests, beliefs, values, opinions, competitor spending habits, future purchase intentions, religion, political affiliation, television viewing habits and a multitude of other lifestyle characteristics essentially relies on voluntary consumer disclosure. The importance of non-transactional data was illustrated in Radford's study, ${ }^{29}$ which described how the Co-operative Bank successfully abandoned its sole use of transactional data in favour of supplementing individual-level lifestyle characteristics to build closer customer relationships, leading to increased profitability.

All modern personalised targeting models, such as neural networks, and all customer profiling and data-appending practices typically incorporate a proportion of voluntarily disclosed individual-level information. Accordingly, the ability of the direct marketing industry to gather and use such information will exercise an increasingly prominent role in sustaining and extending its competitive position. ${ }^{30-37}$

\section{Benefits conferred by individual-level consumer information}

Individual-level information pertains, or specifically relates, to single, identifiable consumers, whereas aggregated consumer classification systems are based on statistical inferences drawn on each individual. Only classification on the basis of detailed, individual-level consumer information enables the development of truly personalised and interactive marketing programmes. ${ }^{38-41}$

Greater detail can be derived from individual-level consumer information such as credit history, financial status, charitable affiliations, hobbies, interests, opinions, product and service preferences and a plethora of other variables. In contrast, aggregated consumer information is mostly derived from group-level national Censuses overlaid with publicly available data sources. ${ }^{42-45}$ Individual-level consumer information is thus more comprehensive and detailed than aggregated information, enabling the identification of hitherto undetected correlations such as the differing value systems and political affiliations that can transcend socio-economic and demographic boundaries. ${ }^{46-49}$ This improves knowledge of consumer behaviour and expands the range of personalised targeting opportunities. ${ }^{50-54}$

Individual-level consumer information also confers a critical advantage over conventional market research. All market research in the UK must be conducted in accordance with the Market Research Society (MRS) 
Individual versus aggregated information code of conduct, which prevents an informant's identity from being revealed without consent to anyone not directly involved in the research. Data collected in consumer research can therefore only be used in an aggregated form for research, modelling or statistical purposes.

It should be noted, however, that a number of collaborative initiatives have been undertaken that have fused individual-level consumer information and market research data. These initiatives exploit the 1995 ruling by the Professional Standards Committee of the MRS, allowing companies to merge market research data with voluntarily disclosed individual-level consumer information subject to certain strict conditions. While the MRS code of conduct precludes the identification of individuals involved in the research, it does permit market research data to be linked to commercial databases for enhancement where individuals on such databases have consented for their information to be used for direct marketing purposes. One such collaboration between Taylor Nelson Sofres (TNS) and Claritas ${ }^{5,56}$ involved using TNS panel data as a donor file for generating propensity models by fusing the data with Claritas's lifestyle data. These models were then used to attribute predictions to each of the Claritas lifestyle respondents who did not feature on the TNS panel database.

The volatility and unpredictability associated with post-modern conditions are increasing the rate at which the accuracy of consumer information decays. The situation is particularly pronounced where consumer information is infrequently updated. ${ }^{57}$ In contrast to Censusbased data, individual-level consumer information is updated continuously through ongoing customer contact, such that a higher degree of accuracy and recency is achieved. ${ }^{58}$

Individual-level consumer information enables the degree of significance of each characteristic to be weighted in relation to the consumer's propensity to respond to a targeted product or service offer. ${ }^{59,60}$ In hierarchically constructed models of this type a response propensity score is assigned to each consumer on the database based on the combined weighting of each characteristic - for example, the combined weighted scores of political affiliation, age and financial status in respect of newspaper readership. The hierarchy thereby provides a powerful predictive tool by forecasting and optimising the responsiveness of consumers to different offers. ${ }^{61-67}$ This is an important benefit since forecasting is a critical issue in establishing product commitment and inventory decisions, and in calculating servicing costs such as call centre staffing levels, prior to the targeting of marketing communications. Improved strategic planning can therefore be achieved.

\section{Voluntary nature of personal information disclosure}

The collection of non-transactional, individual-level information for direct marketing purposes is based on the premise that consumers can be persuaded to disclose personal details voluntarily as a result of some type of marketing exchange process. This is usually in anticipation of some perceived benefit. These exchanges include surveys and questionnaires, direct mail and telephone orders, loyalty cards, product warranty cards, 
replies to direct response ads, sweepstake promotions and rebate and redemption offers. ${ }^{68,69}$

The experience of companies collecting individual-level consumer information within the UK market has demonstrated that a majority of consumers are prepared to disclose such information in various different forms ${ }^{70-73}$ subject to adequate data protection safeguards and evidence of benefits arising from disclosure. ${ }^{74,75}$ In terms of benefits sought, a recent DMA report ${ }^{76}$ revealed these to be principally more relevant offers and personalised levels of service. In the UK alone, millions of consumers voluntarily disclose personal information for direct marketing purposes each year, and the size and wealth of the accumulated information continues to grow.

Though the amount and depth of individual-level consumer information being gathered by businesses continues to expand, encompassing other channels such as point-of-sale and digital routes, this still represents only a proportion of the general population. Clearly, there exists an inherent limitation on the number of consumers who are prepared to disclose personal information voluntarily for direct marketing purposes. Furthermore, individual-level consumer information is derived

\section{Inherent limitations on availability}

from self-selected and therefore non-representative samples. ${ }^{77}$ Whereas the essence of conventional market research lies in obtaining responses from a representative sample of the universe, individual-level consumer information does not constitute a representative and definable sample. It is therefore fundamentally impossible to extrapolate from individual-level consumer information any universally valid statement.

\section{Reliance on demographic data-capture methods}

Typical direct marketing data-gathering practices have relied on the variables of demography, such as age, income, gender, occupation, marital status and family size; geography, usually encompassing postcode regions; receptivity, for example purchase tendency, buying habits, media habits and channel preference; and purchase history, covering frequency, date, location, value and specific items. ${ }^{78,79}$

Demographic characteristics consistently correlate well with purchase likelihood and frequency, and play an important role in target marketing decisions. ${ }^{80-82}$ Receptivity and purchase history contribute insight into purchasing behaviour and represent valuable media correlates. ${ }^{83}$

Demographically based characteristics have therefore tended to form the most commonly collected data variables across the direct marketing industry. ${ }^{84,85}$ The experience of industry practitioners ${ }^{86}$ suggests that those individuals who contribute personal information for direct marketing purposes are demographically representative of the general population. Consequently, the belief that individual-level consumer information is unbiased has led to widespread confidence in the use of such information in customer profiling and other associated applications across the direct marketing industry. But since individual-level consumer information is gathered from self-selected and therefore non-representative samples, there remains the possibility that contributors of such information may in some respects be atypical of the general population. 


\section{Personal interviews}

\section{Methodology}

The objectives of this study were to establish if differences existed between those consumers who voluntarily disclosed personal information compared to those who abstained, and to consider the implications of any emergent differences for direct marketing practice.

It was noted that those consumers who abstained from the disclosure of personal information for direct marketing purposes were naturally least likely to respond to mail and telephone surveys; the results of such surveys would tend to be biased towards contributors of personal information. ${ }^{87}$ The opportunity to explore emergent issues qualitatively was also removed or diminished with these two survey methods.

Personal interviews were therefore chosen as the most appropriate datacollection method, allowing direct marketing data-gathering practices to be explained to respondents such that more complete and informed responses were elicited. In addition, personal interviews facilitated a phenomenological investigation of the underlying reasons for the emergence of differences between contributors and abstainers. Finally, with personal interviews it was possible to record information beyond verbal expression. The nature of words used, facial expressions and body language all communicated emotions, motivations and attitudes not apparent from non-direct methods of data collection, adding greater depth in qualitative understanding. The interviews were conducted in a busy west Yorkshire city centre.

Throughout, reassurance of confidentiality of the results was emphasised and the interviews proceeded in a conversational manner. Responses were collected in writing during the interviews, and further notes added on completion of each interview relating to facial expressions, emotions and feelings. Consistency in manner of question presentation and surroundings was maintained to reduce the context dependency of responses; for example, the immediate environment, interviewee mood, comfort and recent experience.

All individuals eligible to disclose personal information for direct marketing purposes formed the basis of the target population. Effectively this represented almost the entire UK adult population and therefore required a nationally representative sampling frame. In recognition that personal interviews typically have a higher degree of geographic respondent locality and the potential for introducing non-coverage issues such as response bias, ${ }^{88}$ the target population was defined using a proportionately stratified sampling frame.

Stratification of the target population did not imply any departure from the principles of randomness; it merely denoted that the population was divided into a number of strata following completion of the interviews. In order to dispense with the need for weighting and to reduce the number of wasted interviews in the post-interview apportionment process it was desirable for each stratum to be approximately equal in size such that interviewees had a similar probability of inclusion per stratum.

Accordingly, the target population was stratified based on three age bands and gender, comprising a total of six strata. Approximately one-third of the target population was assigned to each age band to ensure that the six 
strata were similar in size. This allowed interviewees to be assigned to each stratum post-interview with little wastage and without the requirement for weighting. In particular, weighting would have affected the assumptions that could be made when interpreting data from the random sample.

Quota sampling as a method of stratification was dismissed because the selection process within strata relies on the discretion of the interviewer. While being an easier method of conducting interviews, this method is more unreliable and prone to bias because it is essentially non-random in nature. Furthermore, pre-selection of individuals for different strata based on characteristics such as age and income would have been inefficient, as much of the personal interview would have been completed before these were confirmed, and the pre-selection process would have been unreliable as it depended on the interviewer's uncertain ability to guess such characteristics in advance.

Individuals were therefore approached as potential interviewees on a random basis regardless of gender, ethnicity, age, outward appearance and

\section{Random sampling} whether alone or in a group. Those individuals walking past a fixed point at one location were asked if they would be willing to participate in the interview process. Children were not approached as they fell outside of the target population. In those cases where an interview commenced and it became apparent that the interviewee was under 18 years of age, then the interview was immediately terminated.

Where a group of two or more individuals was approached, the first individual electing to participate was chosen and this individual was then asked to answer questions in isolation and far enough in distance that responses could not be heard, preventing third-party influence. This was an important procedure, because respondents may have otherwise been tempted to answer in a manner that gave them credibility in the presence of onlookers, rather than providing truthful responses.

On completion of an interview or following declined participation, the next immediate individual passing was approached. This process continued until the time at the disposal of the interviewer on a particular day was exhausted. This procedure was adhered to throughout the entire data-collection exercise, using the same fixed point for approaching interviewees. Essentially, each individual was chosen by chance.

The decision to use a random sample frame and apportion interviewees to strata at the post-interview stage meant that more personal interviews would be required than were actually used in the study. While it was expected that the wastage would be relatively small since the six strata contained similar proportions based on national population characteristics, a total of 275 personal interviews were conducted to ensure that an adequate, proportionately stratified sample frame was obtained.

Table 1 shows the national proportion of individuals within each gender- and age-defined stratum.

The actual proportion of interviewees obtained per stratum is shown in Table 2. Each stratum contained more than 30 interviewees, and each could therefore be considered to be normally distributed. 
Table 1: National proportion of individuals per stratum

\begin{tabular}{|lcc|}
\hline Age group & Male $\%$ & Female $\%$ \\
\hline $18-34$ & 14 & 16 \\
$35-54$ & 18 & 18 \\
55 and over & 16 & 18 \\
\hline
\end{tabular}

Table 2: Actual proportion of interviewees per stratum

\begin{tabular}{|lcccc|}
\hline Age group & Male (no.) & Percentage of total & Female (no.) & Percentage of total \\
\hline $18-34$ & 36 & 13 & 48 & 17 \\
$35-54$ & 46 & 17 & 53 & 19 \\
55 and over & 46 & 17 & 46 & 17 \\
\hline
\end{tabular}

Completed interviews were then assigned to each stratum until the required proportion had been reached, consistent with national representation derived from Table 1. Surplus interviews beyond the required stratum size were not used. Allocation of interviewees to strata based on national representation reduced the total number of interviews used from 275 to 256, as shown in Table 3. Thus, 19 interviews were unused as a consequence of the requirement to apportion interviewees to strata at the post-interview stage.

It was noted that nationally representative results require a minimum sample size in excess of 1,000 respondents. ${ }^{89}$ The results obtained from this study therefore involved a sample size that could not be generalised across the national population. Accordingly, the results of this study are indicative in nature rather than confirmative.

The personal interviews began by informing respondents of common direct marketing data-gathering practices, including consumer surveys and questionnaires, warranty card surveys, telephone and internet registrations and loyalty card applications. Respondents were also advised that the disclosure of personal information for direct marketing purposes could be either voluntary in nature or, if the disclosure was compulsory in meeting a specific objective, for example a mortgage application, then the individual had the option of whether or not to permit the gathering company to use the information subsequently for direct marketing purposes. Interviewees were advised that this latter option was commonly made available in the form of an opt-out box.

Interviewees were then asked if they disclosed personal information for direct marketing purposes, allowing the relative proportions of contributors and abstainers to be established. Those interviewees who

Table 3: Nationally representative proportion of interviewees per stratum

\begin{tabular}{|lcccc|}
\hline Age group & Male (no.) & Percentage of total & Female (no.) & Percentage of total \\
\hline $18-34$ & 36 & 14 & 41 & 16 \\
$35-54$ & 46 & 18 & 46 & 18 \\
55 and over & 41 & 16 & 46 & 18 \\
\hline
\end{tabular}


indicated that they disclosed personal information for direct marketing purposes were asked to describe the reasons influencing their decision, while the underlying reasons for abstention were explored among the remainder. Next, quantitative measurements of each interviewee's occupation, age, gender, gross household income, values and level of data protection concerns were undertaken. Throughout, reassurances of confidentiality were provided and interviewees were encouraged to be truthful in their responses and to answer all questions. Quantitative and qualitative differences between the contributor and abstainer groups were then evaluated.

The purpose of gathering occupation, age, gender and gross household income data was to establish if demographic differences existed between contributors of personal information and abstainers. Measurement of interviewee values was undertaken, because these can transcend and be more predictive than demography alone, ${ }^{90}$ while data protection concerns were measured on the basis that these are central to consumer amenability to disclosure of personal information. ${ }^{91,92}$

On completion of the personal interviews occupation was assigned to the appropriate socio-economic group, shown in Table 4, while age was grouped into the three bands used in the sampling procedure: 18-34, 35-54 and 55 and over. Gross household income was split into five bands: £0-£9,999, £10,000-£19,999, £20,000-£29,999, £30,000$£ 39,999$ and $£ 40,000$ and over. Interviewee gender was completed without a response being sought.

The values characteristics of each interviewee were gathered using a pre-existing scale, the list of values, one of the more commonly used values measurement techniques. This scale is an abbreviated measurement that includes only terminal values and offers a simplified solution to alternative value measurement systems such as Rokeach's value system, which requires the ranking of 18 values. A reduced set of nine terminal values is used in the list of values, which considerably simplified the ranking task for interviewees and thereby reduced response fatigue. The list of values encompasses the variables of self-respect, security, a warm relationship with others, a sense of accomplishment, self-fulfilment, a sense of belonging, being well respected, fun and enjoyment and excitement.

Table 4: Socio-economic groupings

\begin{tabular}{|c|c|c|}
\hline $\begin{array}{l}\text { Social } \\
\text { grade }\end{array}$ & Social status & Occupation \\
\hline A & Upper middle class & Higher managerial, administration or professional \\
\hline B & Middle class & Intermediate managerial, administration or professional \\
\hline C1 & Lower middle class & $\begin{array}{l}\text { Supervisory or clerical, junior managerial, } \\
\text { administration or professional }\end{array}$ \\
\hline C2 & Skilled working class & Skilled manual workers \\
\hline D & Working class & Semi-skilled or unskilled manual workers \\
\hline E & Lowest level of subsistence & $\begin{array}{l}\text { State pensioners or widows, casual or lowest-grade } \\
\text { workers }\end{array}$ \\
\hline
\end{tabular}

Source: $\mathrm{CACl}, 2002$ 
Previous research ${ }^{93,94}$ has shown that using only a top-ranked value as the classification criterion may capitalise on measurement error. More specifically, segments defined by multiple value systems rather than a topranked value were shown to be more reliable and have greater interpretability. Accordingly, this study used a nine-point scale to rank the importance of each value, with 1 representing 'not at all important' and 9 representing 'extremely important'. Only points 1 and 9 were labelled.

The level of data protection concerns among interviewees was measured through the question: 'How concerned are you about how companies collect and use your personal information?' Interviewees were asked to rate their level of concern on a five-point scale, ranging from very concerned through concerned, not sure and unconcerned to very unconcerned. This five-point labelled semantic differential scale provided ease of understanding, an option for expression of neutrality and an acceptable level of within-subject variability.

\section{Results and discussion Incidence of abstention from disclosure}

A total of 157 interviewees (61 per cent) reported that they voluntarily disclosed some form of personal information for direct marketing purposes, while 99 interviewees ( 39 per cent) abstained. Although the results could not be generalised across the national population due to the sample size employed, this finding suggested that there existed a substantial proportion of consumers within the general population who were unwilling voluntarily to disclose personal information.

\section{Differences between contributors and abstainers \\ Quantitative differences}

Differences between the mean scores of the contributor and abstainer groups were measured using the normal distribution, with critical $\mathrm{z}$ values for 5 per cent and 1 per cent significance of \pm 1.96 and \pm 2.58 respectively. The minimum sample size was 99 for the abstainer group, and therefore all cases could be regarded as normally distributed.

Where critical $\mathrm{z}$ values were exceeded then the difference between the means was deemed to be statistically significant using the following hypotheses.

- Null hypothesis $\left(\mathrm{H}_{0}\right)$ : There is no significant difference between the two groups.

- Alternative hypothesis $\left(\mathrm{H}_{\mathrm{A}}\right)$ : There is a significant difference between the two groups.

The results are summarised in Table 5.

The hypothesis that there is no difference in gender between personal information contributors and abstainers could not be tested by differences between means using the normal distribution since the analysis was nonparametric. This was instead measured using the goodness-of-fit chisquare test as shown in Table 6. 
Table 5: Quantitative differences between contributor and abstainer mean scores

\begin{tabular}{|lrrrrrc|}
\hline Value & $\begin{array}{c}\text { Contributors' } \\
\text { mean } \\
\text { score }\end{array}$ & $\begin{array}{c}\text { Abstainers' } \\
\text { mean } \\
\text { score }\end{array}$ & $\begin{array}{c}\text { Critical } \\
\text { value } \\
5 \%\end{array}$ & $\begin{array}{c}\text { Critical } \\
\text { value } \\
1 \%\end{array}$ & $\begin{array}{c}\text { Result } \\
\text { Significant } \\
\text { difference } \\
\text { Yes/no }\end{array}$ \\
\hline Level of concern & 3.82 & 3.92 & \pm 1.96 & \pm 2.58 & +0.81 & No \\
Willingness to disclose & 3.72 & 3.93 & \pm 1.96 & \pm 2.58 & +1.64 & No \\
Occupation & 2.85 & 2.82 & \pm 1.96 & \pm 2.58 & -0.30 & No \\
Age & 43.06 & 42.49 & \pm 1.96 & \pm 2.58 & +1.71 & No \\
Gross household income & 3.22 & 3.23 & \pm 1.96 & \pm 2.58 & +0.06 & No \\
Self-respect & 7.85 & 7.63 & \pm 1.96 & \pm 2.58 & -1.11 & No \\
Security & 7.44 & 6.66 & \pm 1.96 & \pm 2.58 & -3.31 & Yes \\
A warm relationship with & 6.75 & 6.78 & \pm 1.96 & \pm 2.58 & +0.16 & No \\
others & & & & & & \\
A sense of accomplishment & 6.70 & 6.29 & \pm 1.96 & \pm 2.58 & -1.69 & No \\
Self-fulfilment & 6.62 & 6.64 & \pm 1.96 & \pm 2.58 & +0.07 & No \\
A sense of belonging & 6.11 & 6.03 & \pm 1.96 & \pm 2.58 & -0.31 & No \\
Being well respected & 6.69 & 6.76 & \pm 1.96 & \pm 2.58 & +0.31 & No \\
Fun and enjoyment & 7.54 & 7.32 & \pm 1.96 & \pm 2.58 & -0.97 & No \\
Excitement & 6.66 & 6.72 & \pm 1.96 & \pm 2.58 & +0.22 & No \\
\hline
\end{tabular}

Table 6: Gender of personal information contributors

\begin{tabular}{|lccc|}
\hline Gender & Observed number & Percentage & Expected number \\
\hline Male & 70 & 45 & 78.5 \\
Female & 87 & 55 & 78.5 \\
Total & $\mathbf{1 5 7}$ & $\mathbf{1 0 0}$ & $\mathbf{1 5 7 . 0}$ \\
\hline
\end{tabular}

- Null hypothesis $\left(\mathrm{H}_{0}\right)$ : There is no difference in gender between the two groups.

- Alternative hypothesis $\left(\mathrm{H}_{\mathrm{A}}\right)$ : There is a difference in gender between the two groups.

\section{Abstainers are different to contributors}

Table 6 provides a $\chi^{2}$ value of 1.84 . Two levels of significance $(\alpha)$ were assessed: 5 per cent and 1 per cent using one degree of freedom $(v)$ calculated as $(\mathrm{c}-1)(\mathrm{r}-1)=(2-1)(2-1)$. Two critical values were obtained: $\chi_{0.05,1}^{2}=3.84$ and $\chi_{0.01,1}^{2}=6.63$. At both levels of significance the null hypothesis was supported, with no significant difference in gender.

'Security' emerged as a significant difference between the contributor and abstainer groups at both the 5 per cent and 1 per cent levels of significance, with contributors placing a greater level of importance on this attribute than abstainers. This suggested that the former were more likely to view voluntary disclosure of personal information with less dissonance, and with greater reassurance in the security of such information. There were no significant differences between contributors and abstainers with respect to the remaining values, level of data protection concerns, occupation or gross household income.

\section{Qualitative differences}

The two groups differed in their intensity of expression, with abstainers displaying a greater lack of trust and disinterest in the disclosure process than contributors, typified by comments such as: 'I don't trust these 
companies to use my information responsibly' and 'Not interested, it's a waste of time and I don't want to get stacks of junk mail.'

Abstainers were less convinced that their personal information would be held securely and preferred to keep such information private: 'I'm not confident data stays protected if disclosed' and 'Don't trust how they'll use it or who it will be passed on to.'

Scepticism also emerged as a differentiator, with abstainers being more cautious towards the direct marketing industry's activities: 'Waste of time. They just use it to send you junk mail' and 'I'm worried about how the information will be used, like passing it on to companies who then send out junk mail.'

Contributors of personal information were generally more enthusiastic in their tone of response and cited a number of reasons for their readiness for disclosure.

First, an existing customer-company relationship appeared to increase the willingness of interviewees to disclose personal information to that company, primarily because the relationship engendered trust: 'I'd trust them to be responsible based on past experience' and 'I'd be more trusting in how they used my information.'

Secondly, the offer of an incentive motivated those who would otherwise have been indifferent to requests for personal information. The disclosure of personal information was perceived to be a reciprocal exchange process - from an interviewee perspective since such information was known to have a tangible value to the companies collecting it, then these companies were expected to provide recompense: 'Depends what the incentive is. It might give me a nudge to fill something in where I might not be bothered otherwise', 'I love prize draws and free gifts' and 'I am getting something in return and so would be more bothered about filling in my details.'

Thirdly, interviewees were more inclined to disclose personal information where data protection guarantees were evident: 'Tell me what they were using it for and provide guarantees it would not be passed on or used wrongly' and 'Only use it for what they say they'll use it for and not sell it on.'

Finally, interviewees reported a greater willingness to disclose personal information where evidence of longer-term reciprocal benefits was apparent, such as personalised service levels and more relevant and customised product offers: 'If I got better service or they used it to bring out new stuff that was of more interest' and 'Show me what I'd get out of it. How I'd benefit.'

Proclivity for disclosure of personal information was thus influenced by trust in the gathering company to use the information securely and responsibly, and the offer of short-term incentives and evidence of longerterm benefits.

\section{Customer profiling and differences between contributors and abstainers}

Secondary data were obtained from a leading UK mail-order company relating to the use of externally acquired individual-level consumer 
information for customer profiling purposes. For reasons of commercial confidentiality, the identity of the mail-order company and external consumer information provider are not disclosed.

The mail-order company concerned already possessed detailed transactional information on its customers but lacked lifestyle, life-cycle and demographic information needed to understand its customers and those factors underlying purchase behaviours better. For example, age and family composition were believed to be key determinants of product selection. By using external, individual-level consumer information to profile its customer base the company sought to gain a better understanding of its customers' motivations, needs and wants, to increase personalised customer contact, to delineate its product offerings better and to deliver more precise product and service customisation.

A match rate of 33 per cent was achieved between the externally acquired individual-level consumer information and the company's customer base. That is, 33 per cent of the company's customers had at some point voluntarily disclosed detailed personal information through some type of consumer survey, questionnaire or similar device to the external consumer information provider. The remaining 67 per cent of the mail-order company's customers had not disclosed personal information to the provider. The externally acquired information was demographic in nature and did not include values characteristics. It should be noted that the external consumer information provider employed several datacapture routes to acquire such information, rather than relying on one specific channel such as postal surveys, and it had also merged with a number of other commercial consumer databases at the time of this research. In addition, the propensity of the mail-order company's customers to respond to requests for voluntary disclosure of personal information in return for incentives, money-off coupons, sweepstakes, prize draws and mail-in redemption offers was known to be higher than that for the general population. In combination, these factors contributed to the relatively high match rate of 33 per cent.

\section{Implications for customer profiling}

The results of the customer profile demonstrated that the customer base was over-represented with respect to married females with children, aged $35-54$, with a household income of less than $£ 20,000$ per annum. Occupation was biased towards manual workers and housewives. Accommodation was typically rented and lifestyle interests included gambling (football pools and lotteries), fishing, pets, caravanning, camping, gardening, pub visits, catalogue shopping and reading tabloid newspapers.

It was assumed that the 67 per cent of customers who had not disclosed personal information to the external consumer database company exhibited the same overall characteristics as those who had voluntarily contributed such information. This assumption could be calculated with a stated degree of confidence, and inferred demographic characteristics extrapolated to the 'missing' customer data fields. In turn, response propensity scores could be assigned to each customer on the database to aid in the development of demographically based targeting models that forecasted responsiveness to different offers. 'Missing' data could thus be 
compensated for by introducing assumed characteristics based on the matched results. Accordingly, the mail-order company generalised the customer profile findings matched against 33 per cent of its customers across the entire customer base, and used this to guide the development of advertising and promotional messages, tailor marketing communications and provide direction for the catalogue content. This practice is common across the direct marketing industry. ${ }^{95}$

The findings of this study suggest that generalisation of the customer profiling exercise in this manner is deficient because of differences between voluntary contributors of personal information and abstainers. Differences in values and levels of trust and scepticism lead to different response and purchase patterns. For example, early adopters have a greater propensity to purchase technological products such as mobile phones and computers, and are known to possess different values to other groups. Kamakura and Novak, ${ }^{96}$ for example, have shown that the 'security' and 'self-respect' values are in direct opposition: those individuals with higher 'security' values tend to have lower 'self-respect' values. The assumption that the profiled results of a matched section of a customer base can be generalised across the whole customer base is erroneous and potentially leads to the misclassification of segments, prompting a reappraisal of current practice.

There are also implications for the targeting of new customers based on the profiling of a company's current best customers, because in some cases there can be little discrimination between a company's best and worst customers according to demographic profiling criteria alone. For example, the decision to buy life insurance is often based more on a need for security than on personal disposable income. ${ }^{97,98}$ By ignoring differences in values when targeting new customers according to the demographic characteristics of current best customers, companies are potentially overlooking idiosyncratic characteristics that are more predictive of purchase behaviour, leading to a diminution in the effectiveness of targeting models.

\section{Conclusion}

Two limitations in this study should be noted. Firstly, the presence of an interviewer may have influenced the responses provided due to the more intrusive manner of investigation compared to alternative methods. In particular, interviewees may have been more inclined to provide answers that they believed would meet with the approval of the interviewer. Secondly, the results cannot be generalised across the national population due to the sample sizes involved, and should be regarded as indicative in nature rather than confirmative.

The finding that a sizeable minority ( 39 per cent) of consumers abstain from voluntarily disclosing personal information for direct marketing purposes is in broad agreement with prior studies and with the experience of industry practitioners. Those who abstain from the disclosure of personal information are more distrustful of direct marketing activities and tend to be more disinterested, sceptical and less convinced of the benefits conferred by disclosure of such information. 
This suggests that the direct marketing industry can encourage greater levels of voluntary disclosure by educating consumers on the benefits of personalised customer relationships and the delivery of truly customised product and service offers, by seeking to eradicate the damaging perception of the industry's association with 'junk mail' and by building greater trust within the general population. While direct marketers typically focus on the more receptive consumer where the propensity to respond to various direct marketing propositions is greater with a correspondingly higher profitability potential, this should not preclude efforts to connect and engage with more sceptical consumers.

There is no evidence of demographic variation in willingness to disclose personal information voluntarily. While abstainers have slightly greater data protection concerns, the level of concern is not significantly different to those who voluntarily disclose personal information. Companies requesting individual-level consumer information are likely to encounter similar rates of abstention across different age, gender, occupational and income groups. Contributors of personal information assign significantly greater importance to the 'security' value than abstainers. Those individuals who voluntarily disclose personal information are more likely to trust in the responsible use of such information and its security, and be more convinced of the benefits conferred.

This study thus contends that individuals who voluntarily disclose personal information for direct marketing purposes are different to those who abstain both qualitatively and in terms of non-demographically defined characteristics, and that consequently individual-level consumer information is biased towards particular consumer types. The absence of demographic differentiation between abstainers and contributors, long assumed by the direct marketing industry to constitute an absence of bias in individual-level consumer information disclosures, is rooted merely in the system of measurement. This has a number of overlooked implications for direct marketing practice.

First, since voluntarily disclosed individual-level information is likely to be over-representative of consumers with higher 'security' values, and given that those consumers with higher 'security' values are known to have different purchase patterns to those with lower 'security' values, response rates to targeted communications are expected to vary according to the nature of the offer. Given that lower 'security' values tend to be associated with early adopter purchase behaviour, this suggests that companies targeting high-technology electrical products at early adopters will be less successful in recruiting customers using direct marketing techniques that rely on voluntarily disclosed personal information.

Secondly, the critical assumption in customer profiling exercises is that those customers matched against the external consumer database are representative of the entire customer base. In actuality, there are key differences between contributors of personal information and abstainers, and by extension between matched customers and non-matched customers. These overlooked differences potentially result in a misrepresentation of the true characteristics of the overall customer base 
by disregarding significant differences in values that underlie different purchase behaviours. As a consequence, the relevance of personalised marketing messages and the accuracy of product and service customisation are diminished for a proportion of the customer base, leading to a reduction in profitability potential and prompting a reappraisal of extant customer profiling techniques.

\section{Further research}

Generalisation of the results across the national population could be achieved by repeating the study using a sample size in excess of 1,000 personal interviewees.

Larger studies should test the quantitative validity of the observed value difference and, if supported, seek to gain an improved understanding of how and why values influence disclosure proclivity. The findings would have particular relevance for those companies employing individual-level consumer information to target prospects for new products and services, where early adopters have differing values to those of the general population, and for improving the efficiency of customer profiling techniques.

\section{References}

1. Hagel, J. and Rayport, J. F. (1997) 'The coming battle for customer information', Harvard Business Review, January-February, p. 53.

2. Petrison, L. A., Blattberg, R. and Wang, P. (1997) 'Database marketing — Past, present and future', Journal of Direct Marketing, Vol. 11, No. 4, pp. 109-126.

3. Zahavi, J. and Levin, N. (1997) 'Issues and problems in applying neural computing to target marketing', Journal of Direct Marketing, Vol. 11, No. 4, pp. 63-75.

4. Kahan, R. (1998) 'Using database marketing techniques to enhance your one-to-one marketing initiatives', Journal of Consumer Marketing, Vol. 15, No. 5, pp. 491-493

5. McCorkell, G. (1998) 'How marketing went direct', in The Direct Marketing Guide, Vol. 1, Institute of Direct Marketing, Teddington.

6. Fairlie, R. (1998) 'Using customers' demographic and psychographic profiles', in The Direct Marketing Guide, Vol. 1, Institute of Direct Marketing, Teddington.

7. Kelly, S. (2000) 'Analytical CRM: The fusion of data and intelligence', Journal of Interactive Marketing, Vol. 1, No. 3, pp. 262-267.

8. Mitchell, A. (2000) 'In one-to-one marketing, which one comes first?', Journal of Interactive Marketing, Vol. 1, No. 4, pp. 356-357.

9. Robertshaw, G. S. (2000) 'The segmentation and targeting of consumers within the fragmenting UK mail order market', Journal of Segmentation in Marketing, Vol. 4, No. 1, pp. $27-51$.

10. Peltier, J. and Schribrowsky, J. A. (1997) 'The use of need-based segmentation for developing segment-specific direct marketing strategies', Journal of Direct Marketing, Vol. 11, No. 4, pp. $53-63$.

11. Pitta, D. A. (1998) 'Marketing one-to-one and its dependence on knowledge discovery in databases', Journal of Consumer Marketing, Vol. 15, No. 5, pp. 468-480.

12. Petrison et al., ref. 2 above.

13. Kahan, ref. 4 above.

14. McCorkell, ref. 5 above.

15. Mitchell, ref. 8 above.

16. Pitta, ref. 11 above. 
17. Courtheoux, R. J. (2000) 'Database marketing connects to the internet', Journal of Interactive Marketing, Vol. 2, No. 2, pp. 129-137.

18. Micheaux, A. and Gayet, A. (2001) 'Turning a marketing database into a relationship marketing database', Journal of Interactive Marketing, Vol. 2, No. 4, pp. 327-346.

19. Wind, J. and Rangaswamy, A. (2001) 'Customerisation: The next revolution in mass customisation', Journal of Interactive Marketing, Vol. 15, No. 1, pp. 13-32.

20. McCorkell, ref. 5 above.

21. Mitchell, ref. 8 above.

22. Pitta, ref. 11 above.

23. Hagel and Rayport, ref. 1 above.

24. Courtheoux, ref. 17 above.

25. Mitchell, ref. 8 above.

26. Wind and Rangaswamy, ref. 19 above.

27. Zineldin, M. (2000) 'Beyond relationship marketing: Technologicalship marketing', Marketing Intelligence and Planning, Vol. 18, No. 1, pp. 9-23.

28. Dibb, S. (2002) 'Banks, customer relationship management and barriers to the segment of one', Journal of Financial Services Marketing, Vol. 6, No. 1, pp. 10-24.

29. Radford, M. (2004) 'Personal financial services in a digital age', Journal of Consumer Behaviour, Vol. 2, No. 3, pp. 287-296.

30. Kahan, ref. 4 above.

31. Kelly, ref. 7 above.

32. Pitta, ref. 11 above.

33. Micheaux and Gayet, ref. 18 above.

34. Dibb, ref. 28 above.

35. Lix, T. (1995) 'New customer acquisition: Prospecting models and the use of commercially available external data', Journal of Direct Marketing, Vol. 9, No. 4, pp. 9-20.

36. Cerasale, J. (2000) 'US Direct Marketing Association at a public workshop on online profiling co-hosted by the Federal Trade Commission and the US Department of Commerce', available at www.ftc.gov/bcp/workshops/profiling/comments/dma.htm.

37. Hirschowitz, A. (2002) 'Closing the CRM loop: The 21st century marketer's challenge: Transforming customer insight into customer value', Journal of Targeting, Measurement and Analysis for Marketing, Vol. 10, No. 2, pp. 168-179.

38. Hagel and Rayport, ref. 1 above.

39. McCorkell, ref. 5 above.

40. Nowak, G. J. and Phelps, J. (1997) 'Direct marketing and the use of individual level consumer information: Determining how and when privacy matters', Journal of Direct Marketing, Vol. 11, No. 4, pp. 94-108.

41. Feng, Z. (2000) 'The application of fuzzy classification in geodemographic targeting', Journal of Targeting, Measurement and Analysis for Marketing, Vol. 8, No. 1, pp. 45-57.

42. Hagel and Rayport, ref. 1 above.

43. McCorkell, ref. 5 above.

44. Nowak and Phelps, ref. 40 above.

45. Feng, ref. 41 above.

46. Allen, M. W. and Ng, S. H. (1999) 'The direct and indirect influences of human values on product ownership', Journal of Economic Psychology, Vol. 20, No. 1, pp. 5-39.

47. Allen, M. W. (2000) 'The attribute-mediation and product meaning approaches to the influences of human values on consumer choices', in Columbus, F. (ed.) Advances in Psychology Research, Vol. 1, Nova Science Publishers, Huntington, NY, pp. 31-76. 
48. Long, M. M. and Schiffman, L. G. (2000) 'Consumption values and relationships: Segmenting the market for frequency programs', Journal of Consumer Marketing, Vol. 17, No. 3, pp. 214-232.

49. Allen, M. W. (2001) 'A practical method for uncovering the direct and indirect relationships between human values and consumer purchases', Journal of Consumer Marketing, Vol. 18, No. 2, pp. $102-120$.

50. Kahan, ref. 4 above.

51. Kelly, ref. 7 above.

52. Pitta, ref. 11 above.

53. Micheaux and Gayet, ref. 18 above.

54. Cerasale, ref. 36 above.

55. Webber, R. and Sleight, P. (1999) 'Fusion of market research and database marketing', Journal of Interactive Marketing, Vol. 1, No. 1, pp. 9-22.

56. McHugh, L. and Ward, G. (1997) 'Playing our strengths: Successful co-operation between research and database marketing', quoted in ibid.

57. Wang, P. and Splegel, T. (1997) 'Database marketing and its measurement of success', Journal of Direct Marketing, Vol. 8, Spring, pp. 73-81.

58. Micheaux and Gayet, ref. 18 above.

59. Zahavi and Levin, ref. 3 above.

60. Jackson, R. and Wang, P. (1995) Strategic Database Marketing, NTC Business Books, Lincolnwood, IL.

61. Kahan, ref. 4 above.

62. Fairlie, ref. 6 above.

63 Kelly, ref. 7 above.

64. Robertshaw, ref.9 above.

65. Pitta, ref. 11 above.

66. Micheaux and Gayet, ref. 18 above.

67. Lix, ref. 35 above.

68. Fairlie, ref. 6 above.

69. Lix, ref. 35 above.

70. Croft, M. (1997) 'Facts of life (lifestyle databases)', Marketing Week, 1 May, pp. 43-45.

71. Reed, D. (1999) 'Consumer lifestyle data', Precision Marketing, 8 February, pp. 7-9.

72. Gofton, K. (1999) 'Data firms react to survey fatigue', Marketing, 29 April, pp. 16-18.

73. Henley Centre (1995) Quoted in The Direct Marketing Guide, Vol. 1, Institute of Direct Marketing, Teddington, p. 9.

74. Kleinman, M. (1999) 'News analysis', Precision Marketing, 16 November., pp. 11-12.

75. Croft, ref. 70 above.

76. Direct Marketing Association (2004) 'DMA launches top line findings of its survey into consumer attitudes towards direct marketing', available at dma.org.uk.

77. Fairlie, ref. 6 above.

78. Ibid.

79. Copp, V. F. (1997) 'Re-inventing direct marketing', Journal of Direct Marketing, Vol. 11, No. 4, pp. 14-25.

80. Fairlie, ref. 6 above.

81. Peltier and Schribrowsky, ref. 10 above. 


\section{Abstainers and contributors of personal information}

82. Harrison, T. (1994) 'Mapping customer segments for personal financial services', International Journal of Bank Marketing, Vol. 12, No. 8, pp. 17-25.

83. Peltier and Schribrowsky, ref. 10 above.

84. Hagel and Rayport, ref. 1 above.

85. Lehman, D. R., Gupta, S. and Steckel, J. H. (1998) Marketing Research, Addison-Wesley, New York.

86. Croft, ref. 70 above

87. Lehman et al., ref. 85 above.

88. Ibid.

89. Ibid.

90. Allen, ref. 49 above.

91. Petrison et al., ref. 2 above.

92. O'Malley, L., Patterson, M. and Evans, M. (1997) 'Intimacy or tntrusion? The privacy dilemma for relationship marketing in consumer markets', Marketing Management, Vol. 13, No. 6, pp. $541-560$.

93. Kamakura, W. A. and Novak, T. P. (1992) 'Value-system segmentation: Exploring the meaning of LOV’, Journal of Consumer Research, Vol. 19, June, pp. 119-132.

94. Kahle, L. R. and Kennedy, P. (1989) 'Using the list of values (LOV) to understand consumers', Journal of Consumer Marketing, Vol. 6, No. 3, pp. 5-12.

95. Croft, ref. 70 above.

96. Kamakura and Novak, ref. 93 above.

97. Harvey, J. W. (1990) 'Benefit segmentation for fund raisers', Journal of the Academy of Marketing Science, Vol. 18, Winter, pp. 77-86.

98. Holt, D. B. (1997) 'Poststructuralist lifestyle analysis: Conceptualizing the social patterning of consumption in post-modernity', Journal of Consumer Research, Vol. 23, March, pp. 326-350. 